\title{
EFFECT OF UNCERTAINTY ON THE FATIGUE RELIABILITY OF REINFORCED CONCRETE BRIDGE DECK UNDER HIGH STRESS LOADS
}

\author{
U. T Osumeje ${ }^{1}$, A. Ocholi' ${ }^{2}$, J. M. Kaura ${ }^{3,}{ }^{*}$ and A. O. Abdulhamid ${ }^{4}$

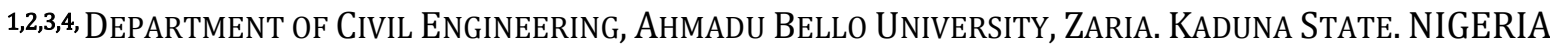 \\ E-mail addresses: 1 tomred23@gmail.com,2 amanaocholi@gmail.com, 3 jmkaura@abu.edu.ng, \\ 4 ozovehea@gmail.com
}

\begin{abstract}
The deterioration of reinforced concrete bridge deck that has been damaged as a result of load action can affect the durability, safety and function of the structure. In this paper, a reliability time-variant fatigue analysis and uncertainty effect on the serviceability of reinforced concrete bridge deck was carried out. A simply supported 15m bridge deck was specifically used for the investigation. Mathematical models were developed and the uncertainties in structural resistance, applied loadings as well as the structural components were accommodated using probabilistic method. The limit state functions were evaluated using the First Order Reliability Algorithm and the entire process was implemented using a developed MATLAB program called Rayswit.m. Failure in the deck shear region gave the most critical effect with a reliability index range of 6.95 to -12.38 when compared to flexure region with an index of 8.58 to -10.53 .
\end{abstract}

Keywords: Fatigue, cracks, structural reliability, uncertainties, high stress loads

\section{INTRODUCTION}

Bridges which serve as a major link component in the infrastructure system, are extremely vulnerable to this action of fatigue. This action could possibly lead to major threats on structural safety and lead to catastrophic failure [10]. With increase in potential deterioration and much heavier vehicle loads, the safety of the existing deteriorating bridge decks in the later life cycle is more critical [15].

It is impossible to take on-site measurement for every concerned location of every bridge. As such, finite element method (FEM) based structural dynamic analysis can be used to provide reasonable stress range histories for bridge details in various scenarios [1].

Not only inbridge deck deterioration is an economic problem, it is also a risk to those who traverse the structure. Forms of deterioration can range from slightly damaged deck surfaces, causing unpleasant sights and decreasing bridge deck serviceability, up to spalling of large pieces of concrete that reduces the structural integrity and it can be a danger for the public. Therefore, there is a compelling need to understand the behavior of bridge decks under service load and develop a reliable procedure and analysis to assess the serviceability of the deck, which will then serve as a decision-making tool for the rehabilitation or the replacement of the decks [2].

\subsection{Fatigue Effect on Bridge}

The deterioration of concrete bridge decks that have been directly damaged by traffic loads affects their durability, safety, and function. Structural damage can increase, such as residual deformation and numerous cracks, which eventually decreases the life of the deck as well as its load carrying capacity [13].

It is fairly difficult to rehabilitate the fatigue resistance of a deck because the shear strength that has been decreased by repeated loads must be improved with the flexural strength.

Although numerous research programs over the past decade have attempted to understand fatigue response and to establish a fatigue model for concrete subjected to repeated loads, the fatigue failure characteristics of strengthened concrete structures are not yet systematically established on a scientific foundation [9]. 
Currently the linear elastic finite element analyses method is mainly used in the design of reinforced concrete bridge decks. Since the load effects on the bridge superstructure are sought for by a multitude of load combinations, this approach is suitable. However, some uncertainties relate to such an analysis [7].

\subsection{Uncertainties}

Structural engineering analysis and design is replete with uncertainties, some of which are obvious and some others may never have been considered. These uncertainties can be categorised into two, either as a result of acquired knowledge or by chance and they have their sources from some of the following: Time, Statistical Limits, Model Limits, Load Variation and Human Errors. The Allowable Stress Design and the Load Resistance Factor Design codes take some aspect of Statistical Limit, Load Variation, Time and Modelling. Others such as Human Errors must be dealt with using quality control methods such as review and construction inspection [14].

The main objective of this research is to develop a model and program that predicts the behavior of a reinforced concrete bridge deck subjected to high stress live load cycle using an advanced Finite Element MATLAB program called "Rayswit.m" and assess uncertainty effect on its performance at the serviceability level.

Reliability indices are computed for the serviceability limit states for a wide time variant condition. The results of the reliability analysis will serve as a basis for a critical evaluation of the eurocode provisions, proposed modifications and recommendations.

\section{MATERIALS AND METHOD}

\subsection{Estimation of Parameters for Reliability of Bridge Deck}

The load component of highway bridges can be divided into several groups, such as dead load, live load, (static and dynamic), environmental loads (temperature, wind, earthquake, earth pressure, ice) and other loads (collision, braking load). Load components are treated as random variables, their variation is described by a cumulative distribution function (CDF), a mean value and a coefficient of variation [8]. The basic load combination for highway bridges considered in this study is the combination of dead load, live load and dynamic load(HA and HB Loadings).

\subsection{Bridge Model}

The case study used was a simply supported bridge deck made of two equal spans of $15.0 \mathrm{~m}$ each which cover an effective length of $30.0 \mathrm{~m}$ and is located in an open area. It is characterized by an open cross section composed of seven (7number) precast reinforced concrete longitudinal beams set at constant spacing of $1.70 \mathrm{~m}$. The upper flanges of the precast longitudinal beams are duly connected to a $0.20 \mathrm{~m}$ deep in-situ deck slab cast on a $0.05 \mathrm{~m}$ thick precast concrete slab formwork. Giving a deck slab thickness of $0.25 \mathrm{~m}$. The superstructure is integrated with the sub structure via bearing pads. The foundation for the bridge consists of cast in-situ reinforced concrete piles with pile caps. The total width of the bridge is $11.0 \mathrm{~m}$. The carriage way is $7.3 \mathrm{~m}$ wide and has a walkway on each side of $1.5 \mathrm{~m}$ wide.

\subsection{Structural Materials}

Materials were chosen according to Eurocode 2, part 2 , concrete is class C40/C50, while steel reinforcement steel is S500.

Unit weight of concrete $\gamma=25.0 \mathrm{KN} / \mathrm{m}^{3}$, Unit weight of Asphalt concrete $=23.5 \mathrm{KN} / \mathrm{m}^{3}$

Weight of parapet wall $=0.5 \mathrm{KN} / \mathrm{m}$

\subsection{Limit State Evaluation}

The provisions in the design of reinforced concrete structures in Eurocode 2 are deterministic with partial safety factors to accommodate uncertainties. However, the most efficient way to accommodate uncertainties in structural analysis is by using reliability method [12].

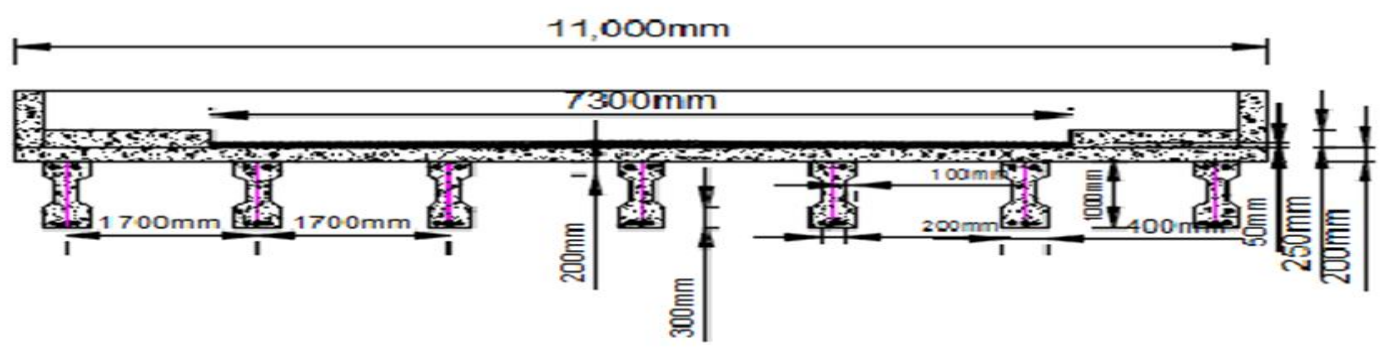

Figure 1.A Cross-section through the Bridge deck 
Reliability based analysis technique is a probabilistic process where loads and strengths of structural materials and sections are represented by their known or postulated distributions, defined in terms of distribution types, mean and standard deviations [11]. Reliability analysis here is used to test the effect of uncertainties in structural designs.

In this study, the capacity loss of reinforced concrete member due to shear and flexure was considered, and their limit state functions were developed. The following limit state functions were evaluated using first order reliability method;

The dead load moment is:

$$
\begin{aligned}
& M_{d l}=\frac{G_{k} l^{2}}{8} \\
& \begin{aligned}
M_{d l}=0.125[ & \left(0.25 \times 1 \times 25 \phi_{c}\right) \\
& \left.+\left(0.04 \times 1 \times 23.5 \phi_{a s p h}\right)\right] \times 1.7^{2} \\
& =2.26 \phi_{c}+0.34 \phi_{\text {asph }}
\end{aligned}
\end{aligned}
$$

The live load moment $M_{l l}$ per meter width of slab is

$$
M_{l l}=\alpha_{Q}\left(\frac{Q_{k} l}{32}\right)+\alpha_{q}\left(\frac{q_{k} l^{2}}{8}\right)=8.98 \emptyset_{Q k}
$$

Total applied moment,

$$
\begin{aligned}
& M_{E d}=M_{d l}+M_{l l} \\
& \quad M_{d l}=2.26 \phi_{c}+0.34 \phi_{a s p h}+8.98 \phi_{Q k}
\end{aligned}
$$

Design capacity of the slab from Eurocode, $M_{R d}=$

$$
\emptyset_{R} A_{s} f_{y d}\left(d-\left(\frac{A_{s} f_{y d}}{2 b f_{c d}}\right)\right)
$$

Therefore the limit state equation is

$$
\begin{aligned}
G\left(x_{1}\right)=\emptyset_{R} A_{s} f_{y d} & \left(d-\left(\frac{A_{s} f_{y d}}{2 b f_{c d}}\right)\right) \\
- & \left(2.26 \emptyset_{c}+0.34 \emptyset_{a s p h}\right. \\
+ & \left.8.98 \emptyset_{Q k}\right)
\end{aligned}
$$

\subsection{Limit State Function for Shear in Interior Beam}

The dead load shear is

$$
\begin{array}{r}
V_{d l}=\frac{G_{k} l}{2}=0.5\left(14.25 \emptyset_{c}+0.94 \emptyset_{\text {asph }}\right) 15 \\
=107 \emptyset_{c}+14.1 \emptyset_{\text {asph }}
\end{array}
$$

To obtain the critical live load shear, the LM1 (Load Model 1, according to eurocode) is placed with the point load over the support as shown in Figure 2.

Critical shear for live load $\mathrm{V}_{\mathrm{u}}$ is;

$$
\begin{aligned}
V_{u}=\frac{Q_{k}(2 L-2)}{L} & +\frac{Q_{k} L}{2}=V_{u} \\
& =\left(\frac{150(2 \times 15-2)}{15}\right. \\
& \left.+\frac{15.3 \times 15}{2}\right) \emptyset_{Q}=394.8 \emptyset_{Q}
\end{aligned}
$$

Applied shear stress $V_{E d}$ is;

$$
\begin{aligned}
V_{-}(E d)=\left[\left(V_{-} d l\right.\right. & \left.\left.+V_{-} u\right) / b d\right]=V_{-}(E d) \\
& =\left(\left(107 \emptyset_{-} c+14.1 \emptyset_{-} a s p h\right.\right. \\
& \left.+394.8 \emptyset_{-} Q\right) \\
& / b d)
\end{aligned}
$$

Therefore, the limit state function is; $G\left(x_{-} 2\right)=0.138 f_{-} c k\left(1-f_{-} c k / 250\right)-\left[\left(107 \emptyset_{-} C\right.\right.$

$$
\left.\left.+14.1 \emptyset_{-} a s p h+394.8 \emptyset_{-} Q\right) / b d\right]
$$

Limit State Function for Flexure in Interior Beam The resultant moment due to dead load is;

$$
\begin{aligned}
M_{-} d l=G k l^{\wedge}(2) & M_{-} d l=\left(G_{-} k l^{\wedge} 2\right) / 8 \\
& =0.125 x \llbracket 15 \rrbracket^{\wedge} 2(14.25 \Phi c \\
& +0.94 \Phi a s p h) \\
& =401 \emptyset_{-} C+26.4 \emptyset_{-} \text {asph }
\end{aligned}
$$

The resultant moment due to live load:

$$
\begin{gathered}
M_{l l}=\left[\mathrm{M}_{\mathrm{Qk}}+\mathrm{M}_{\mathrm{qk}}\right] \\
M_{q k}=\left(\frac{\alpha_{q k}\left(1.7 \times q_{k}\right) L^{2}}{8}\right)=0.125 \times 0.8 \times 15.3 \times \\
=344.3 \emptyset_{Q}
\end{gathered}
$$

To get $\mathrm{M}_{\mathrm{Qk}}$ from LM1, the maximum bending moment occurs in the section on which one of the two tandem axles is applied at a distance from the beam mid-point equal to half that between the aforesaid axle and the resultant of the moving load train is shown in the Figure 3.

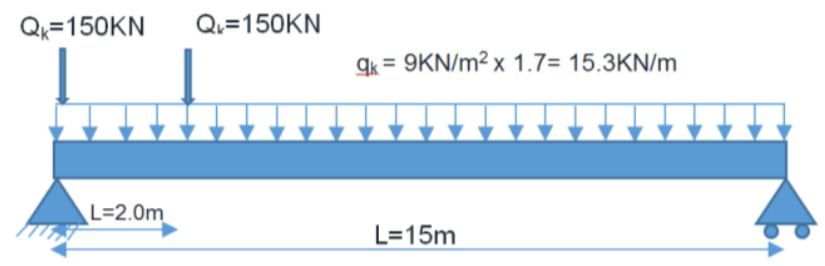

Figure 2: Arrangement of LM1 for critical shear

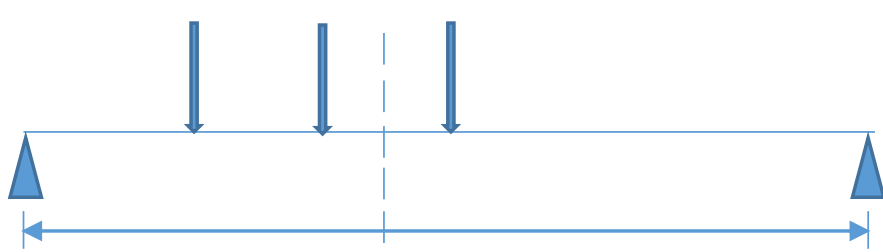

Figure 3: Arrangement of point of maximum bending of LM1

Therefore, the maximum bending moment on the beam would occur in the section and is given by

$$
M_{\max }=M_{(s)}=\frac{R}{4}\left[l-2 \times C+\frac{C^{2}}{L}\right]
$$

So, by applying the resultant of the pair of tandem axles corresponding to the midline, we obtain a constant bending moment between the concentrated loads as;

$$
\begin{gathered}
M_{-} \max ^{\wedge^{\prime}}=R / 4(L-2 C), \text { For LM1 } C=1.2 / 2= \\
0.6 \mathrm{~m} \text { and } \mathrm{L}=15 \mathrm{~m}
\end{gathered}
$$


Where $R=\left(Q_{k}+Q_{k}\right)=150+150=300 K N$

Therefore;

$$
\begin{gathered}
M_{\max }=\frac{\alpha_{Q k}}{4} R(L-2 C) \\
=\left(\frac{0.8 \times 300}{4}\left(15-\frac{2 \times 1.2}{2}\right)\right) \emptyset_{Q} \\
=M_{Q k}=828 \emptyset_{Q} \\
M_{L L}=M_{q k}+M_{Q k}=(344.3+828) \emptyset_{Q} \\
=1172.3 \emptyset_{Q} \\
M_{E d}=M_{d l}+M_{L L} \\
=401 \emptyset_{c}+26.4 \emptyset_{\text {asph }} \\
+1172.3 \emptyset_{Q}
\end{gathered}
$$

Therefore the limit state function is;

$$
\begin{aligned}
G\left(x_{3}\right)=A_{s t} f_{y k} & \left(d-\frac{A_{s t} f_{y k}}{2 b f_{c k}}\right) \emptyset_{R} \\
& -\left(401 \emptyset_{c}+26.4 \emptyset_{\text {asph }}\right. \\
& \left.+1172.3 \emptyset_{Q}\right)
\end{aligned}
$$

In the above equations, $G\left(x_{1}\right)$ is the equation for Failure Mode One under Flexure in the deck slab, $G\left(x_{2}\right)$ is the equation for Failure Mode Two under Shear in the deck beam, $G\left(x_{3}\right)$ is the equation for Failure Mode Three under Flexure in the deck beam. $\emptyset_{R}$ is the model uncertainty for resistance, $\emptyset_{c}$ model uncertainty due to concrete, $\emptyset_{\text {asph }}$ model uncertainty due to asphalt, $\emptyset_{Q}$ model uncertainty due to imposed (traffic) load, $f_{y k}$ steel strength, $A_{s t}$ area of steel reinforcement, $f_{c k}$ concrete strength, $\mathrm{b}$ width of section, $d$ effective depth.

\subsection{Computer Analysis Procedure}

The Rayswit.m MATLAB program was encoded using the First Order Reliability algorithm (as can be seen in the Figures 4 and 5) on the simply supported RC bridge deck. The program was used to evaluate the limit state functions (equations (7), (11) and (20)), and the probabilities of failure as well as safety indices under fatigue failure modes of flexure and shear were recorded in accordance with the Eurocode specifications by varying the following parameters;

i. The variation of deck slab (concrete and asphalt) depth (200 - 300mm).

ii. The coefficient of variation with respect to the

\begin{tabular}{|c|c|c|c|c|c|}
\hline S/No & Design Variables & Notation & Unit & $\begin{array}{l}\text { Distribution } \\
\text { Model }\end{array}$ & Mean and COV \\
\hline 1 & $\begin{array}{l}\text { Resistance Model } \\
\text { Uncertainty }\end{array}$ & $\Phi_{R}$ & - & Normal & $(1.0 ; 0.05)$ \\
\hline 2 & $\begin{array}{l}\text { Concrete Load Model } \\
\text { Uncertainty }\end{array}$ & $\Phi_{c}$ & - & Normal & $(1.0 ; 0.05)$ \\
\hline 3 & $\begin{array}{l}\text { Asphalt Load Model } \\
\text { Uncertainty }\end{array}$ & $\Phi_{\text {asph }}$ & - & Normal & $(1.0 ; 0.05)$ \\
\hline 4 & $\begin{array}{l}\text { Traffic Load Model } \\
\text { Uncertainty }\end{array}$ & $\Phi_{Q}$ & - & Normal & $(1.0 ; 0.05)$ \\
\hline 5 & $\begin{array}{l}\text { Concrete Compressive } \\
\text { Strength }\end{array}$ & $f_{c d}$ & $\mathrm{~N} / \mathrm{mm}^{2}$ & Lognormal & $(30 ; 0.05)$ \\
\hline 6 & Steel Strength & $f_{y d}$ & $\mathrm{~N} / \mathrm{mm}^{2}$ & Lognormal & $(500 ; 0.05)$ \\
\hline 7 & Area of Steel & $A_{s}$ & $\mathrm{~mm}^{2}$ & & Nominal \\
\hline 8 & Width of Slab & $b$ & $\mathrm{Mm}$ & Normal & $(1000 ; 0.05)$ \\
\hline 9 & In-situ Slab Thickness & $h$ & $\mathrm{Mm}$ & Normal & $(250 ; 0.05)$ \\
\hline 10 & Effective Depth & $d$ & $\mathrm{Mm}$ & Normal & $(219 ; 0.05)$ \\
\hline 11 & Width of Beam & $b$ & $\mathrm{Mm}$ & Normal & $(400 ; 0.05)$ \\
\hline 12 & Beam Height & $h$ & $\mathrm{Mm}$ & Normal & $(1000 ; 0.05)$ \\
\hline 13 & Effective Depth & $d$ & $\mathrm{Mm}$ & Normal & $(937 ; 0.05)$ \\
\hline
\end{tabular}
traffic load model uncertainty under slab flexure condition (5\% - 20\%).

iii. The variation of the depth of beam with respect to shear $(1.0-1.2 \mathrm{~m})$.

iv. The coefficient of variation with respect to beam shear in the concrete strength (5\% - 20\%).

v. The coefficient of variation with respect to the strength model uncertainty under beam flexure condition (5\% - 20\%).

Table 1. Generation of Stochastic Parameter for the Limit State Function in the program 


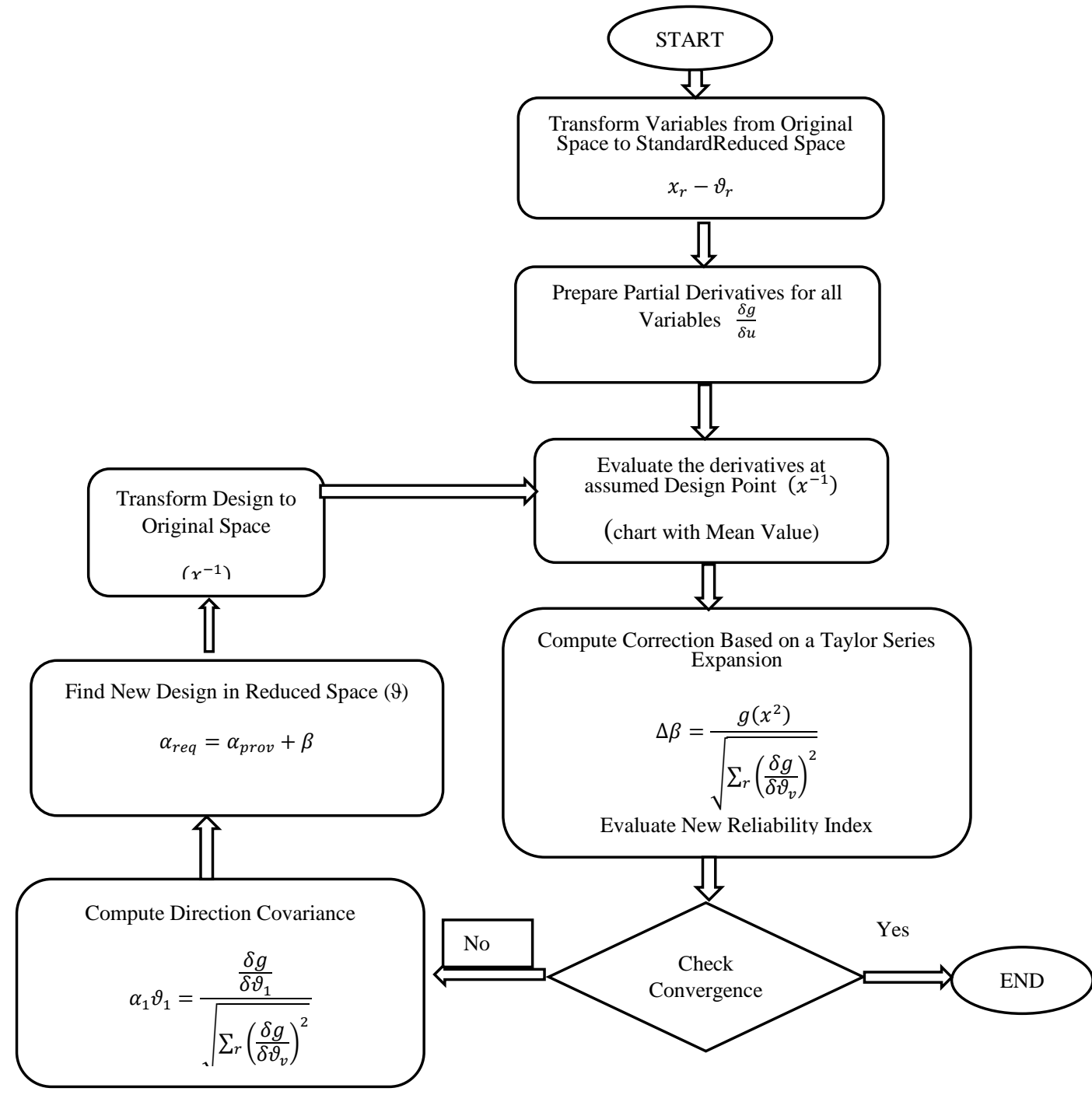

Figure 4: Flow Chart for MATLAB Implementation of the FORM

Reliability analysis was carried out in this study for the investigation of the effect of uncertainties on the fatigue behaviour of reinforced concrete bridge deck. The First Order Reliability Method was evaluated and safety indices were generated using time discretization strategy with the developed MATLAB program 'Rayswit.m', for a stress range of 2-10 load cycles/min and the results discussed below.

\section{RESULTS AND DISCUSSION}

\subsection{Effect of Coefficient of Variation due to Traffic Load Model Uncertainty}

Figures 6 and 7 show the relationship between the safety index and the stress cycle for different Traffic Load Model Uncertainty scenarios in the deck slab region under flexure. After the structural member is opened to traffic, the safety index(which is the probability measure of structural capacity) drops from the range of 8.56 to 5.59 to that of 1.26 , to -6.04 at stress cycles of 2, 4, 6 and 8 cycles/min for a period of 10, 15, 20 and 30 years respectively at $5 \%$ covariance. Also the reliability index dropped from 8.56 to -7.5 after 2 cycles/min and 10 cycles/min for a period of 10 and 30 years to traffic. In this research, the $5 \%, 10 \%$ and $20 \%$ coefficient of variations indicate excellent, average and poor quality control/measures respectively and their effects on the safety index being observed. The increase in fatigue exposure time then leads to a decrease in structural capacity of the deck slab to resist applied loading.

\subsection{Effect of Deck Slab Depth Variation on the Safety Index with Respect to Stress Cycle under Flexure Condition.}

Figures 8 - 10 show the relationship between the safety index and the stress cycle for different depth scenarios in the deck slab region under flexure. At 10years and 10 stress cycles/min, the section was safe as it displayed positive safety index values, but after 20 years and above to traffic load, the reliability displayed a non-linear decrease in safety index range from a value of -4.92 to 9.98, -1.09 to -2.67 and 1.26 to -2.67 for slab depths of 150,200 and $250 \mathrm{~mm}$ respectively at 6 stress cycle/min and 20 to $30 y e a r s$ respectively to traffic. 


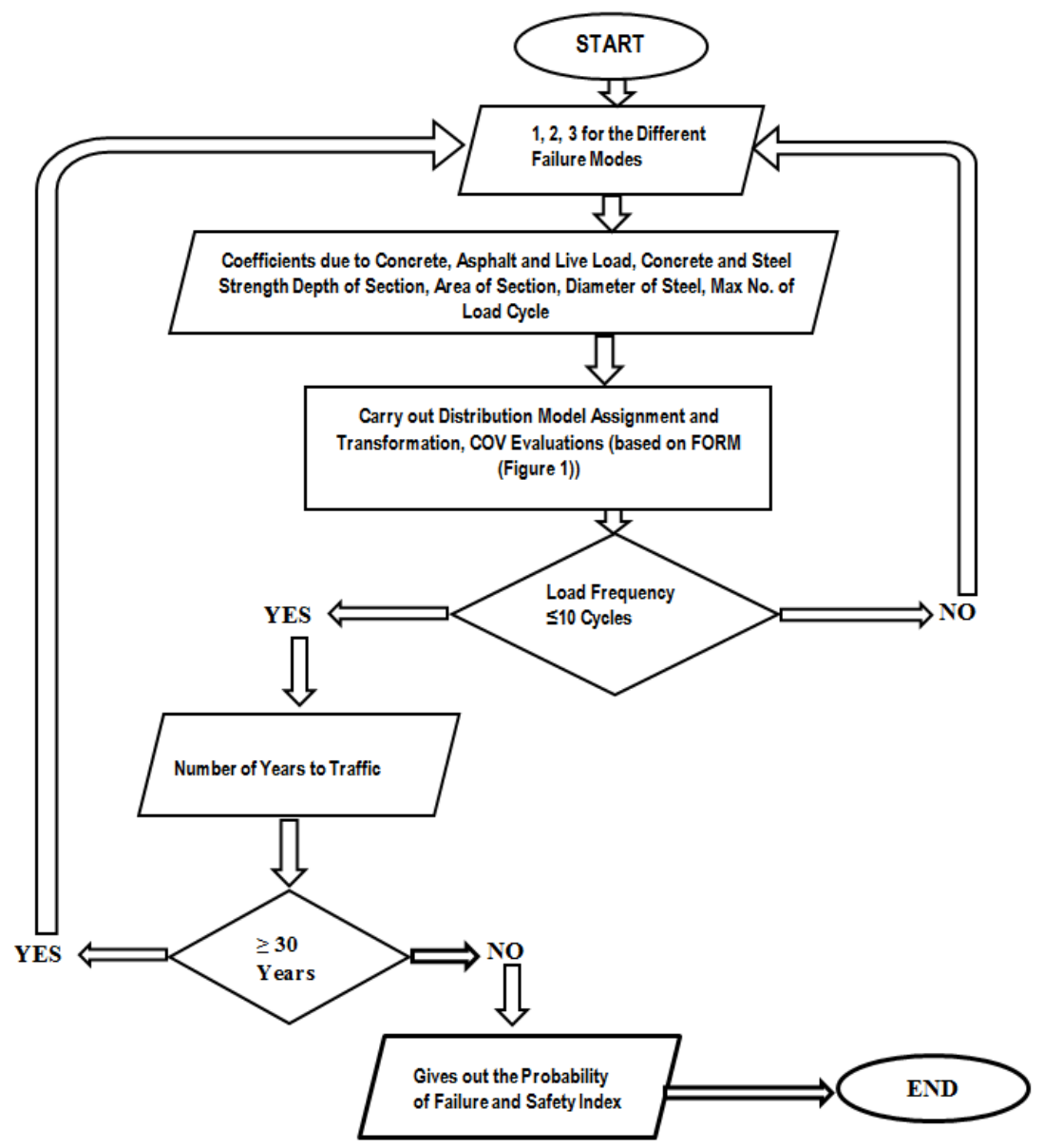

Figure 5: Flow Chart for generating safety index

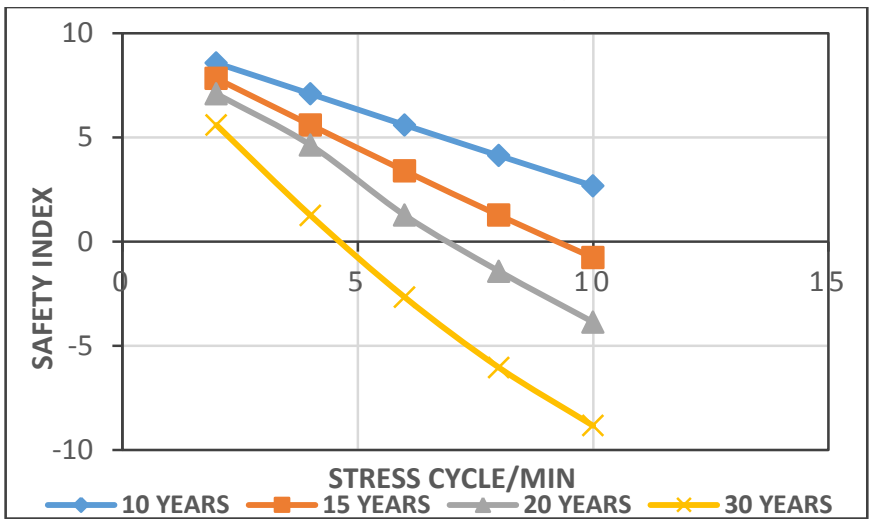

Figure 6.Slab Flexure Safety Index Vs Stress Cycle/min at 5\% Traffic Load Covariance

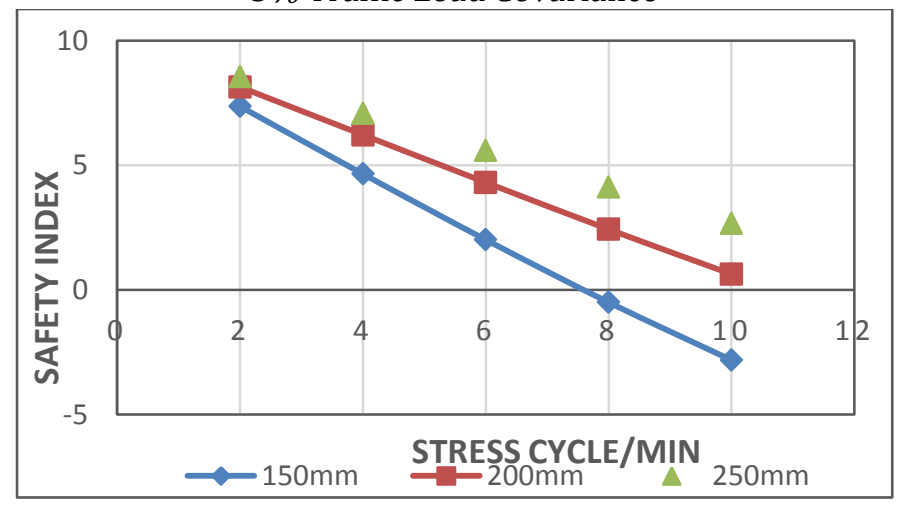

Figure 8.FlexureSafety Index Vs Stress Cycle/min at 10 years for Various Slab Depths

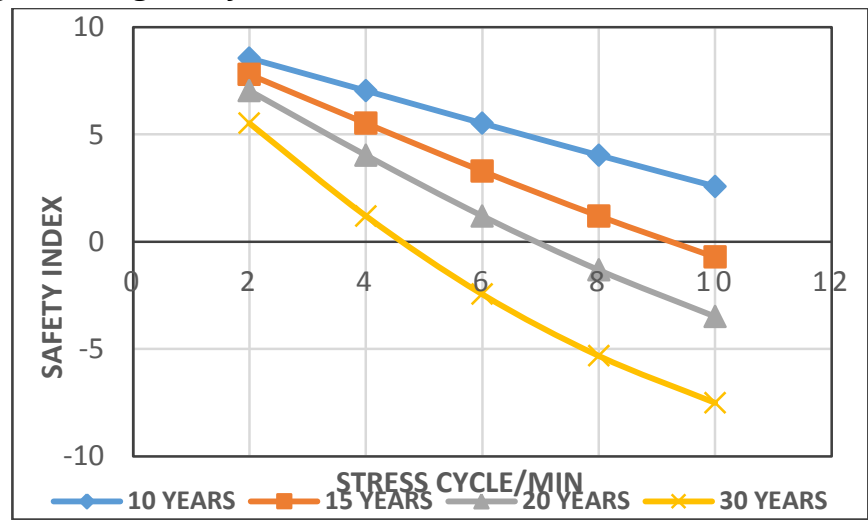

Figure 7. Slab Flexure Safety Index Vs Stress Cycle/min at 10\%Traffic Load Covariance.

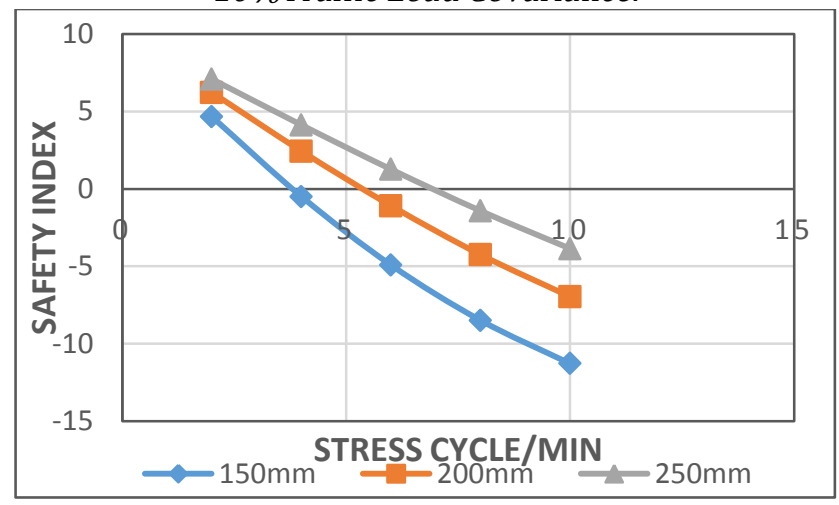

Figure 9. Flexure Safety Index Vs Stress Cycle/min at 20 years for Various Slab Depths 


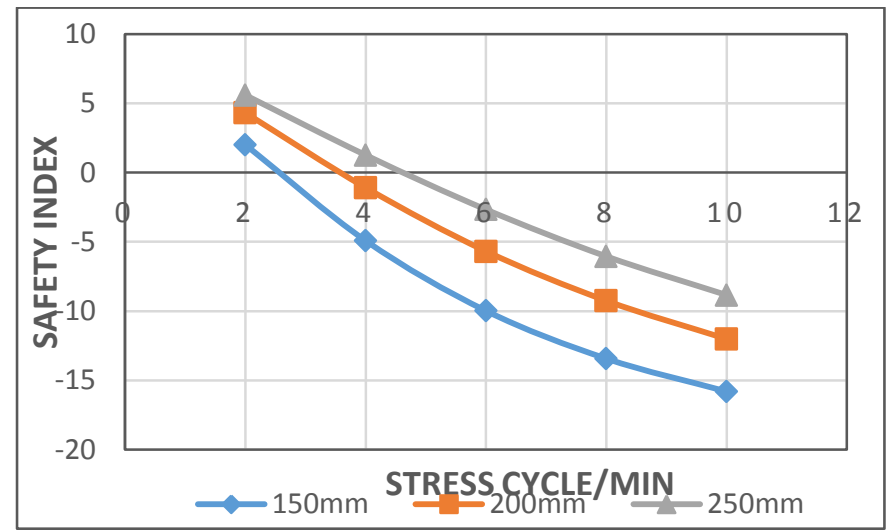

Figure 10.FlexureSafety Index Vs Stress Cycle/min at 30years for Various Slab Depths

\subsection{Effect of Beam Depth Variation on the Safety Index with Respect to Stress Cycle under Condition of Shear Stress.}

Figures 11 and 12show the variation of beam shear reliability with the depths of section. As the stress cycle increases, the reliability displayed a nonlinear reduction. At a stress level of 6 cycles $/ \mathrm{min}$, the respective reliability indices are 3.22, 3.92, 4.49 after 10 years and $-6.35,-5.10,-4.49$ after $30 y e a r s$ at depths of $1000 \mathrm{~mm}, 1100 \mathrm{~mm}$ and $1200 \mathrm{~mm}$ respectively. Thus, this is a clear indication that the larger the

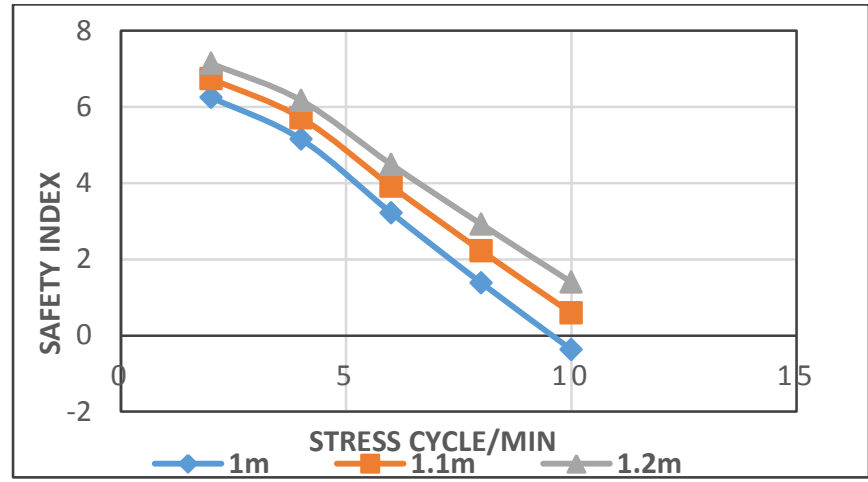

Figure 11.ShearSafety Index Vs Stress Cycle/min at 10 years for Various Beam Depths

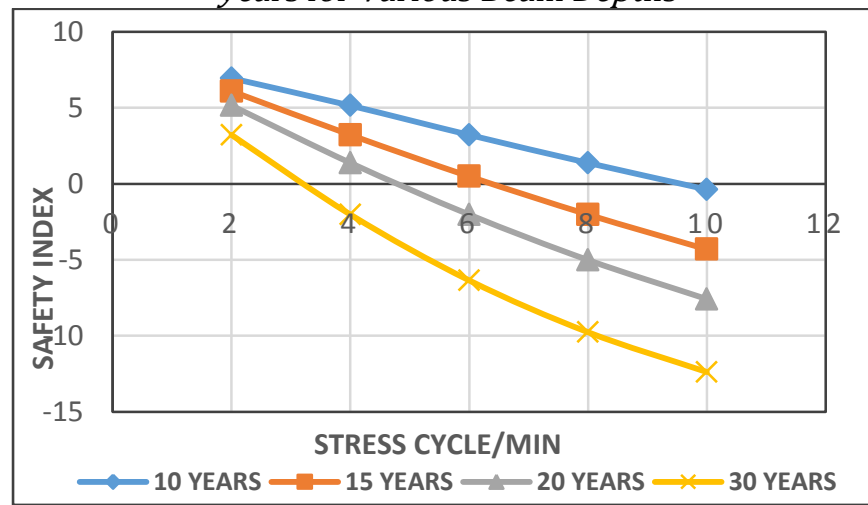

Figure 13.ShearSafety Index Vs Stress Cycle/min at 5\% Concrete Strength Covariance section the more resistant the member is to fatigue and after 30 years and at 6 cycles/min the member failed indicating that it has reached its ultimate fatigue life.

\subsection{Effect of Concrete Strength Uncertainty on the Safety Index with respect to the Stress Cycle}

Figures 13and 14show the variation of beam reliability and stress cycle with respect to the coefficient of variation of concrete strength uncertainty. At $5 \%$ strength covariance, the reliability index value of deck beam under shear condition was $3.22,1.38,0.49,-0.37$ at $2,4,6$ and 10 cycles $/ \mathrm{min}$ after $30,20,15$ and 10 years to traffic. It is therefore clear from the plots that, in addition to fatigue, the coefficient of variation of concrete strength action also has significant effect on the safety of the reinforced concrete member. These effect of uncertainties in the form of coefficient of variation can only be captured when reliability method is employed in the analysis and design as regards to the current provisions of the Eurocode 2, which is deterministic and hence, conservative.

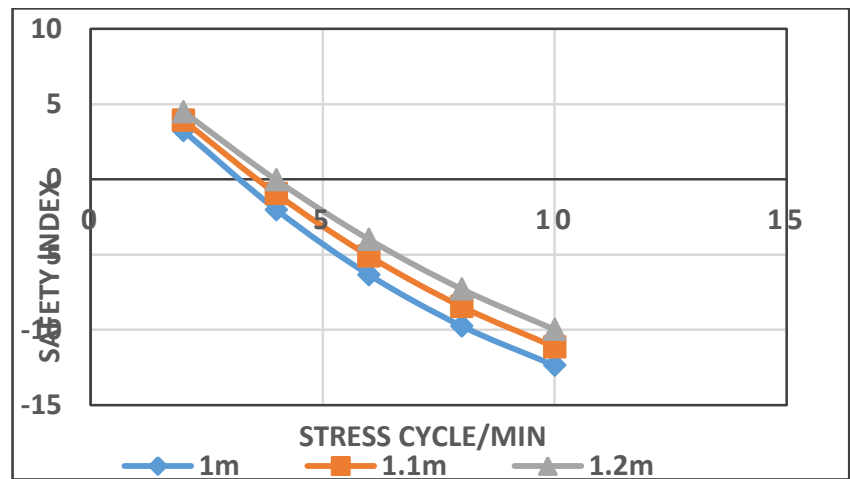

Figure 12. Shear Safety Index Vs Stress Cycle/min at 30 year for Various Beam Depths

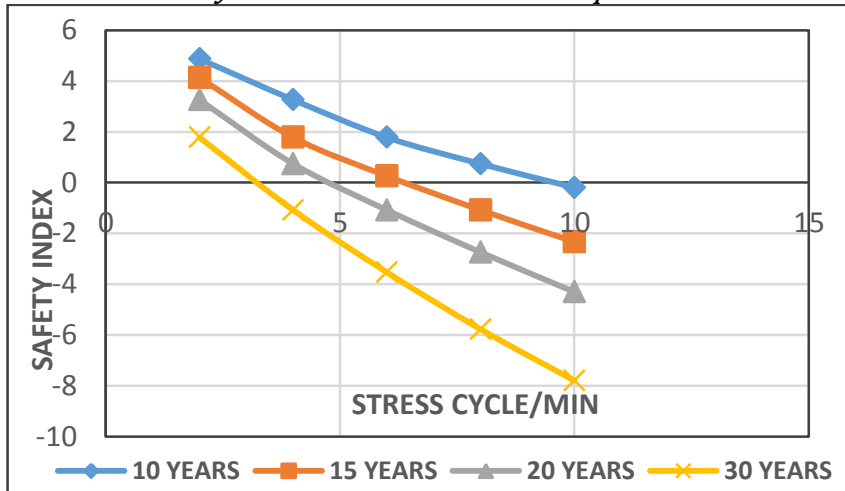

Figure 14. Safety Index Vs Stress Cycle/min at 20\% Concrete Strength Covariance 


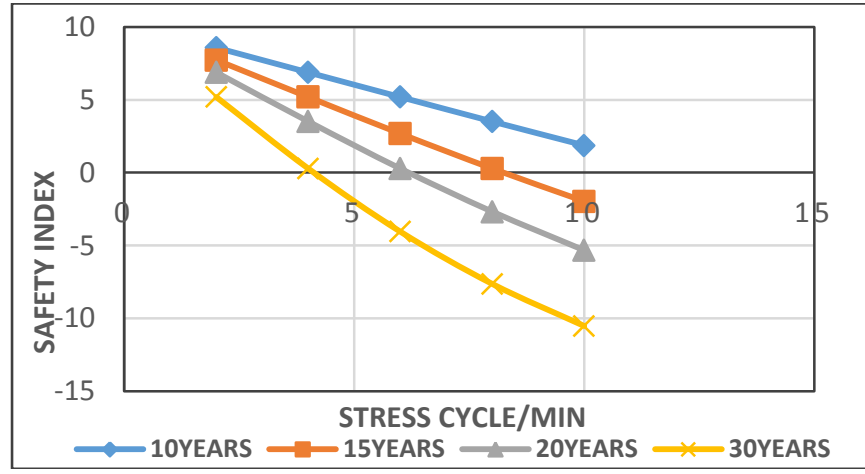

Figure15.FlexureSafety Index Vs Stress Cycle/min at 5\% Beam Strength Covariance

\subsection{Effect of Strength Model Uncertainty on the Safety Index with respect to the Stress Cycle under Condition of Flexure.}

Figures 15 and 16 show the variation of reliability index and stress cycle with respect to beam strength model uncertainty. As the strength covariance increased up to $10 \%$, the safety index dropped from 5.19 at $5 \%$ covariance to 3.91 at $10 \%$ after 2 cycles/in after 30years to traffic. However, the large difference in safety index value is a clear indication of time dependent fatigue effect on the reinforced concrete structure. When fatigue is initiated, it is only a matter of time the entire load carrying capacity of the bridge superstructure under stress will be lost, thereby leading to danger to life and properties. Thus the issue of fatigue in reinforced concrete must be giving serious attention, especially when the structure is located in a high density traffic area.

\section{CONCLUSION AND RECOMMENDATIONS}

In this paper, the probabilistic method was used to assess the effects of uncertainty in the fatigue behaviour of reinforced concrete bridge deck. The mathematical model for the capacity loss and their respective limit sate function were developed based on the recommendations of Eurocode. The limit state functions were evaluated using the First Order Reliability Algorithms. The entire process was implemented using a developed MATLAB program called Rayswit.m. In conclusion,

I. Failure due to the shear in the deck beam gave the most critical section, as it had the lowest reliability index range of value from 6.95 at 2 cycles/min to -12.38 at 10 cycles/min after 10 and 30 years of loading when compared with 8.58 at 2 cycles/min to -10.53 at 10 cycles/min under flexure condition.

II. It was clearly established that failure in reinforced concrete bridge superstructure subjected to

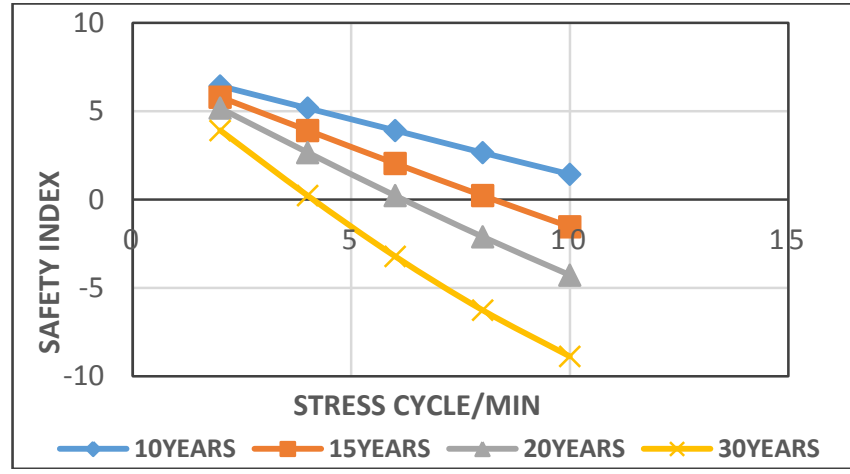

Figure 16. Flexure Safety Index Vs Stress Cycle/min at 10\%Beam Strength Covariance

fatigue is a very serious durability problem that cannot be ignored.

III. The presence of uncertainties further worsen the situation due to the random nature of applied loadings and design parameters involved that define the structural resistance.

Therefore, the following recommendations can be made;

1. Since cracks in reinforced concrete members lead to destruction/failure of the section as well as spalling of deck section, proper quality control should be addressed and adequate serviceability checks carried out. Recent investigations have confirmed that the use of polymer plates or fibre reinforcement in concrete section to prevent corrosion of cracked sections and increase the strength to weight ratio of the structural section.

2. To make appropriate conservative assumptions in complex analyses, this technique can sometimes be difficult, for instance, leaving out nonstructural elements is not always conservative

3. Reliability based methods should be incorporated into the Eurocode 2 design criteria for reinforced concrete structures subjected to fatigue so as to accommodate the uncertainties in structural design parameters, since the present code use the deterministic method of partial safety concept.

\section{REFERENCES}

[1] Blejwas T. E., Feng C. C., Ayre R. S. Dynamic interaction of moving vehicles and structures. J Sound Vib; 67:513-21, 1979.

[2] David Ferrand. Reliability analysis of a reinforced concrete deck slab supported on steel girders. Materials. University of Michigan. English 2005.<tel-00474728.

[3] Eurocode 0: Eurocode-basis of structural design. Brussels: CEN., 2006. 
[4] Eurocode 1: Actions on structures - part 2: Traffic loads on bridges. Brussels: CEN, 2006.

[5] Eurocode 2: Design of reinforced concrete structures- Part 1-1: General rules and rules for buildings. Brussels: CEN, 2008.

[6] Fang I. K., Worley J. A, Burns N. H, Klinger R. E. Behavior of isotropic reinforced concrete bridge decks on steel girders. Journal of Structural Engineering, 116(3):659-78, 1990.

[7] Fredrik D. Shear force design of reinforced concrete bridge decks. Design choices and their influence on the final design. Chalmers University of Technology SE-412 96 Göteborg Sweden., 2014.

[8] Handbook 4,. "Design of Bridges" Guide to basis of bridge design related to Eurocode, Leonardo Da Vinci Pilot ProjectCZ/02/B/F/PP-134007, 2005.

[9] Jongsung S., Hongseob O, Structural behavior of strengthened bridge deck specimens under fatigue loading. Journal of Engineering Structures 26. pp 2219-2230, 2004.
[10] Le Rose C. The collapse of the silver bridge. West Virginia Hist. Soc Quart, XV (4), 2001.

[11] Melchers R. E., "Structural reliability analysis and prediction", $2^{\text {nd }}$ edition. John Wiley, Chichester, 1999.

[12]Melchers R. E, "Assessment of existing structuresapproaches and research needs" Journal of Structural Engineering, 127(4), 406-411, 2001.

[13] Schla "fli M, Bru "hwiler E. Fatigue of existing reinforced concrete bridge deck slabs. Journal of Engineering Structures; 20 (11): 991-8. 1998.

[14] William M. B., Uncertainty in structural engineering. Practice Periodical on Structural Design and Construction. ASCE. 2008.

[15] Zhang W., Yuan H..Corrosion fatigue effects on life estimation of deteriorated bridges under vehicle impacts. Journal of Engineering Structures, 71. pp 128-136, 2014. 